\title{
Experiencia en el rediseño curricular del Programa en Contaduría y Alta Dirección: una visión de la profesión contable hacia la tercera década del siglo XXI
}

Recibido: 20 de julio de 2013

Aprobado: 30 de agosto de 2013

José Gerardo de la Vega Meneses ${ }^{1}$

De la Vega, J. G. (2013). Experiencia en el rediseño curricular del Programa en Contaduría y Alta Dirección: una visión de la profesión contable hacia la tercera década del siglo XXI. Activos 21, 87-135.

Clasificación JEL: Z 19

\section{Resumen}

El presente documento plasma la experiencia de la Universidad Popular Autónoma del Estado de Puebla en el rediseño curricular del programa académico Licenciatura en Contaduría y Alta Dirección. Proceso que requirió identificar las características esenciales e indispensables del perfil del Licenciado en Contaduría o Contador Público. Este programa curricular se basó de manera primordial en las competencias que requiere el profesional del mundo de la contaduría en el ámbito internacional y sin perder de vista las necesidades sociales locales y regionales que de esta profesión se demanda. Este procedimiento de rediseño también consideró que el estudiante fuera capaz de desarrollar las competencias básicas y disciplinares

1 Universidad Popular Autónoma del Estado de Puebla. 21 sur 1103, Colonia Santiago, Puebla, México, C.P. 72160. Tel: (222) 22994 00, ext. 7757; fax: (222) 232 52 51. Correo electrónico: josegerardo.delavega@upaep.mx 
para dar respuesta eficiente a las necesidades requeridas por la sociedad, en un contexto de continuo cambio y en una economía con perspectivas alentadoras para las próximas décadas: México.

\title{
Palabras clave
}

Diseño curricular, competencias, estructura curricular.

De la Vega, J. G. (2013). The Experience in the re-design of the Accounting and Senior Management Program: a vision of accouintinng profession into the third decade of XXI century. Activos 21, 87-135.

\begin{abstract}
This paper has been developed in order to share the experience at Universidad Popular Autónoma del Estado de Puebla during the redesign process of its academic program entitled Licenciatura en Contaduría y Alta Dirección (Bachelor's Degree in Accounting and Senior Management). This redesign process required to identify essential features according to the profile required by qualified accounting academic degree programs in Puebla, México and Latin-American universities. Also, this redesigned curriculum takes into account the competences required by the professional accountants at international level and considering the social needs at local and regional level required for this profession. This redesign of the related academic program also promotes that the student becomes able to develop the basic and professional skills of the accounting discipline in order to efficiently respond to the needs required by society in a context of constant change. This academic program allows the student to become to a professional accountant well prepared to succeed in an economy with encouraging prospects and opportunities for the coming decades: Mexico.
\end{abstract}

\section{Keywords}

Curricular design; competences; curriculum framework. 
De la Vega, J. G. (2013). Expérience dans la réforme du Programme d'études Comptables et Direction Générale : Une vision de la profession comptable vers la troisième décennie du vingtième siècle. Activos 21, 87-135.

\section{Résumé}

Le document présent élabore l'expérience de l'Université Populaire Autonome de l'Etat de Puebla, dans la réforme du programme détudes académiques, Licence en Comptabilité et Direction Générale. Ce processus a exigél'identification des caractéristiques essentielles et indispensables du profil du Licencié en Comptabilité ou Expert-Comptable. Ce programme d'études s'est basé de façon primordiale, sur les compétences nécessaires au professionnel dans le monde de la comptabilité, dans le domaine international et sans perdre de vue les besoins sociaux, locaux et régionaux, que demandent cette profession. Cette procédure de réforme a tenu compte également, de la capacité de létudiant à développer les compétences basiques requises par la société, dans un contexte de changement continu et une économie aux perspectives réconfortantes pour les prochaines décennies: Mexique.

\section{Mots clés:}

Reforme programme détudes, compétences, structure du programme d'études. 


\section{Introducción}

En el proceso para identificar las necesidades sociales que debe atender un profesional Licenciado en Contaduría y Alta Dirección, se estableció como estrategia principal el desarrollo de diversas reuniones en Academia, en las cuales participaron profesionales de firmas de contadores de alcance local, nacional e internacional, empleadores, egresados, especialistas de la profesión contable y académicos investigadores que han concurrido a diversos congresos de la disciplina contable.

Para identificar los requerimientos sociales, los miembros participantes en el rediseño de la Licenciatura en Contaduría y Alta Dirección se reunieron para reflexionar, discutir y opinar sobre estas necesidades considerando los contextos regional, nacional einternacional, de tal manera que se identificó de manera específica la forma en que el egresado de la Licenciatura debe atenderlas, además de contribuir a la solución de problemáticas propias de la profesión enfatizando los atributos requeridos para desempeñarla con éxito.

\section{Identificación de necesidades sociales}

Las necesidades de las entidades, sean públicas o privadas, demandan mayor responsabilidad social para los profesionales de la contaduría, y en consecuencia los Licenciados en Contaduría y Alta Dirección deben atender a las siguientes exigencias sociales:

- La sociedad requiere servicios de alta calidad basados en sólidos conocimientos científicos y técnicos propios de la disciplina y de otras áreas relacionadas con la administración de negocios, que resulten en optimizar la toma de decisiones en un entorno de control y necesidad de administración eficiente de los recursos.

- La sociedad requiere que los profesionistas de la contaduría brinden servicios con servicio de espíritu al bien común, asumiendo el desempeño de la profesión con responsabilidad moral. 
- La sociedad requiere servicios de los profesionistas de la contaduría que sean realizados con cuidado y diligencia, honradez y rectitud.

- La sociedad requiere servicios de los profesionistas de la contaduría reconocidos por los organismos reguladores y profesionales en la materia.

- La sociedad requiere que los profesionistas de la contaduría sean capaces de brindar información útil para accionistas, inversores y en general, para los mercados financieros, empleados, e incluso, las autoridades gubernamentales, con fines de toma de decisiones pertinentes.

- La sociedad requiere profesionistas de la contaduría capaces de desempeñar sus conocimientos y habilidades para generar información con respecto a los distintos tipos de entidades con objeto de reflejar aspectos sociales sobre los que impactan sus actividades y que atañen a la comunidad social, al medio ambiente y cuestiones éticas.

En este contexto se identificó claramente que los Licenciados en Contaduría y Alta Dirección requieren ser profesionales calificados con conocimientos y capacidades que les permitan, con posterioridad al egresado, obtener certificaciones que garanticen la calidad de sus servicios hacia el sector público y privado en donde se desempeñen, y a la sociedad en general, teniendo la tarea primordial de ser los líderes en las acciones de generación de información financiera y no financiera de las entidades, estableciendo por anticipado los controles necesarios para estos propósitos de tal manera que se logre administrar los riesgos y fomentar la sustentabilidad de la entidad.

En el proceso se identificó que es común que las certificaciones formen parte fundamental en los criterios de contratación de servicios contables. En este sentido, resaltamos cuatro organismos de certificación mediante los cuales los profesionales de la contaduría pueden obtener un certificado competente. En primer lugar, el Instituto Mexicano de Contadores Públicos 
(2014) certifica por disciplinas a: contabilidad gubernamental; contabilidad y auditoría gubernamental; contabilidad; finanzas; y fiscal. En segundo lugar, el Instituto Mexicano de Auditores Internos (2014) ofrece la certificación en estos campos profesionales: auditor interno certificado; auditor gubernamental profesional certificado; certificación en autoevaluación de control; auditor de servicios financieros certificado; y certificación en aseguramiento en la gestión del riesgo. En tercer lugar y con respecto a las tecnologías de la información, Microsoft (2014) ofrece la certificación Microsoft Office Specialist. Certifica la capacidad de combinar las tecnologías Web para ampliar el modo en el que se crea y se consume información, así como la capacidad de construir aplicaciones flexibles y seguras. En cuarto lugar, la Asociación Mexicana de Intermediarios Bursátiles (2014) ofrece la certificación para operadores de bolsa y apoderados de valores, brindando estas opciones de certificación: promotor de sociedades de inversión; promotor de valores; asesor en estrategias de inversión; operador de bolsa; y operador del mercado de dinero.

Otra necesidad social también está representada porque el Licenciado en Contaduría y Alta Dirección sea capaz de investigar e innovar con miras a generar aportaciones útiles en asesoramiento y consultoría de las micro, pequeñas, medianas y grandes empresas, contribuyendo a la correcta implementación de sistemas contables, de costos y presupuestos, así como de evaluaciones financieras para efectos de decisiones de inversión.

A su vez, una necesidad social que debe ser provista por el profesional de la contaduría es que genere información de cualquier entidad económica, información vital para cualquier proceso de toma de decisiones, independientemente de la magnitud o sector al que pertenezca la entidad a la que se brindan los servicios.

El profesional de la contaduría también debe ayudar a las entidades en el fortalecimiento de los controles y la eficiente gestión de riesgos, en la tarea de contribuir al desarrollo sustentable a largo plazo y contribuir al desarrollo competitivo del país. 


\section{Análisis de la demanda existente}

Con respecto a la demanda existente de profesionistas contables, de entre los cuales se corresponde a los Licenciados en Contaduría y Alta Dirección, y con base a un análisis realizado a las licenciaturas relacionadas con la Contaduría en México, se obtuvieron los resultados que se observan en la tabla 1:

Tabla 1. Contexto de la demanda existente en el estudio de programas académicos relacionados con la Licenciatura en Contaduría en México

\begin{tabular}{ll}
\hline \multicolumn{1}{c}{ Característica } & \multicolumn{1}{c}{ Descripción } \\
\hline Total de materias obligatorias & Entre 34 y 58 \\
\hline Total de materias optativas & Entre 2 y 11 \\
\hline Duración de la Licenciatura & Entre 4 a 7,5 años \\
\hline $\begin{array}{l}\text { Contenidos mínimos } \\
\text { indispensables considerados } \\
\text { en los programas }\end{array}$ & $\begin{array}{l}\text { Conocimientos en contabilidad y finanzas; } \\
\text { en organización empresarial y negocios; y en } \\
\text { tecnologías de la información. }\end{array}$ \\
\hline $\begin{array}{l}\text { Estructura curricular del plan } \\
\text { de estudios }\end{array}$ & $\begin{array}{l}\text { Áreas de formación general; de formación } \\
\text { sustantiva o profesional; y de formación integral } \\
\text { profesional. }\end{array}$ \\
\hline $\begin{array}{l}\text { Principales líneas terminales } \\
\text { consideradas en asignaturas } \\
\text { optativas }\end{array}$ & $\begin{array}{l}\text { Auditoría, internacional, finanzas y } \\
\text { administración. }\end{array}$ \\
\hline $\begin{array}{l}\text { Asignaturas generalmente } \\
\text { programas }\end{array}$ & $\begin{array}{l}\text { Contabilidad internacional; auditoría interna } \\
\text { presuperacional; contabilidades especiales, } \\
\text { formulación y evaluación de proyectos de inversión. }\end{array}$ \\
\hline
\end{tabular}

Fuente: elaboración propia con datos de los programas académicos analizados.

En el proceso de rediseño se indagó acerca del contexto general del campo laboral para el desarrollo de los profesionales de la contaduría. Entornos en los cuales los estudiantes de Contaduría y Alta Dirección 
aspiran a progresar, en un ámbito de cada vez más protagonismo y aplicando sus amplios conocimientos en la práctica profesional, en vinculación con la atención de los problemas sociales, y contribuyendo al desarrollo del país. Acorde a la información del Observatorio Laboral de la Secretaría del Trabajo y Previsión Social (2014), el comportamiento de las profesiones y ocupaciones en México en las cuales se desempeña un Licenciado de la profesión contable se resume en la tabla 2.

Tabla 2. Indicadores estratégicos del campo profesional de la contaduría en México (estimaciones a 2013)

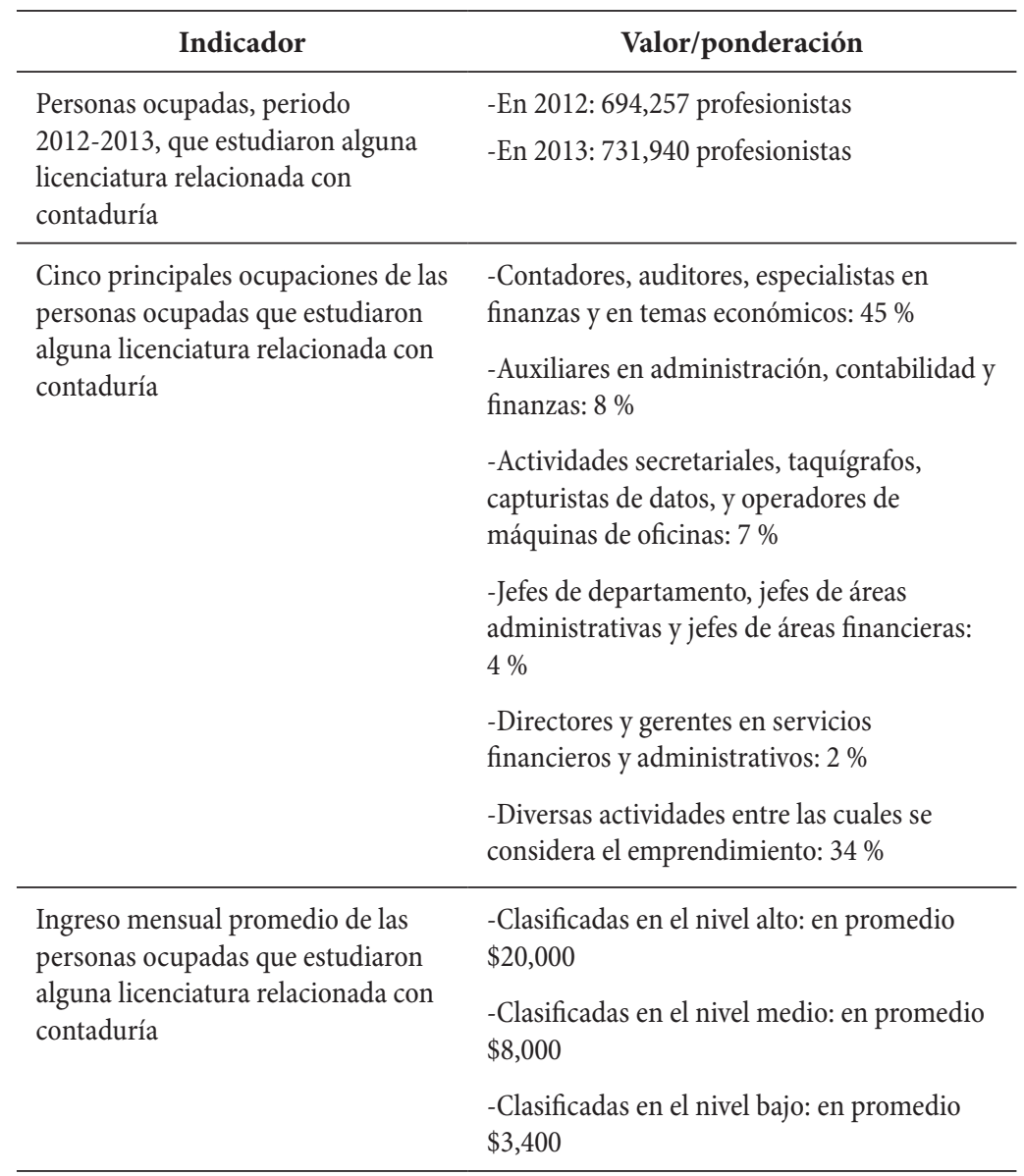




\begin{tabular}{|c|c|}
\hline Indicador & Valor/ponderación \\
\hline \multirow{6}{*}{$\begin{array}{l}\text { Actividad económica en que se } \\
\text { desempeñan las personas ocupadas } \\
\text { que estudiaron alguna licenciatura } \\
\text { relacionada con contaduría }\end{array}$} & $\begin{array}{l}\text {-C32\%: En servicios profesionales, } \\
\text { financieros y corporativos }\end{array}$ \\
\hline & $-18 \%$ : En el comercio \\
\hline & $\begin{array}{l}-12 \% \text { : En el gobierno y organismos } \\
\text { internacionales }\end{array}$ \\
\hline & $-12 \%$ : En la industria manufacturera \\
\hline & $-8 \%$ : En servicios sociales \\
\hline & $-18 \%$ : En otros sectores \\
\hline $\begin{array}{l}\text { Sector de propiedad en que se } \\
\text { desempeñan las personas ocupadas } \\
\text { que estudiaron alguna licenciatura } \\
\text { relacionada con contaduría }\end{array}$ & $\begin{array}{l}80 \% \text { en el sector privado y } 20 \% \text { en el sector } \\
\text { público }\end{array}$ \\
\hline $\begin{array}{l}\text { Género de las personas ocupadas } \\
\text { que estudiaron alguna licenciatura } \\
\text { relacionada con contaduría }\end{array}$ & $46 \%$ mujeres y $54 \%$ hombres \\
\hline \multirow{4}{*}{$\begin{array}{l}\text { Distribución porcentual por edades, } \\
\text { personas ocupadas que estudiaron } \\
\text { alguna licenciatura relacionada con } \\
\text { contaduría }\end{array}$} & $-6 \%$ : entre 20 y 24 años \\
\hline & $-28 \%$ : entre 25 y 34 años \\
\hline & $-33 \%$ : entre 35 y 44 años \\
\hline & -33\%: más de 45 años \\
\hline \multirow{5}{*}{$\begin{array}{l}\text { Distribución geográfica, personas } \\
\text { ocupadas que estudiaron alguna } \\
\text { licenciatura relacionada con } \\
\text { contaduría }\end{array}$} & $\begin{array}{l}\text {-36\% se localiza en la región centro: Distrito } \\
\text { Federal, Hidalgo, México, Morelos, Puebla y } \\
\text { Tlaxcala. }\end{array}$ \\
\hline & $\begin{array}{l}\text {-21\% se localiza en la región centro } \\
\text { occidente: Aguascalientes, Colima, } \\
\text { Guanajuato, Jalisco, Michoacán, Nayarit, } \\
\text { Querétaro, San Luis Potosí y Zacatecas. }\end{array}$ \\
\hline & $\begin{array}{l}\text {-16\%: se localiza en la región noreste: } \\
\text { Coahuila, Chihuahua, Durango, Nuevo León } \\
\text { y Tamaulipas. }\end{array}$ \\
\hline & $\begin{array}{l}-11 \% \text { se localiza en la región noroeste: Baja } \\
\text { California Norte y Sur, Sinaloa y Sonora. }\end{array}$ \\
\hline & $\begin{array}{l}\text { - } 16 \% \text { se localiza en la región sur-sureste: } \\
\text { Campeche, Chiapas, Guerrero, Oaxaca, } \\
\text { Quintana Roo, Tabasco, Veracruz y Yucatán. }\end{array}$ \\
\hline
\end{tabular}




\begin{tabular}{|c|c|}
\hline Indicador & Valor/ponderación \\
\hline \multirow{3}{*}{$\begin{array}{l}\text { Duración promedio en el empleo, } \\
\text { personas ocupadas que estudiaron } \\
\text { alguna licenciatura relacionada con } \\
\text { contaduría }\end{array}$} & -75 \%: más de 3 años \\
\hline & $-22 \%$ : de 1 a 3 años \\
\hline & $-3 \%$ : menos de 1 año \\
\hline \multirow{5}{*}{$\begin{array}{l}\text { Resumen de indicadores, personas } \\
\text { ocupadas que estudiaron alguna } \\
\text { licenciatura relacionada con } \\
\text { contaduría }\end{array}$} & $-79 \%$ son asalariados \\
\hline & $-46 \%$ son mujeres \\
\hline & $\begin{array}{l}\text {-35 \% trabajan en la zona centro (Puebla } \\
\text { pertenece) }\end{array}$ \\
\hline & $\begin{array}{l}-32 \% \text { laboran en servicios profesionales, } \\
\text { financieros y corporativos }\end{array}$ \\
\hline & $\begin{array}{l}\text { - } 45 \% \text { se ocupan como contadores, auditores, } \\
\text { especialistas en finanzas y en asuntos } \\
\text { económicos }\end{array}$ \\
\hline
\end{tabular}

Fuente: elaboración propia con datos del Observatorio Laboral de la Secretaría del Trabajo y Previsión Social (2014).

Ahora bien, con respecto al Estado de Puebla los principales indicadores de los profesionistas ocupados relacionados con la Licenciatura en Contaduría son los siguientes (ver tabla 3):

Históricamente, el mercado de la educación superior es el que ha experimentado un mayor crecimiento en México en las últimas décadas, y ofrece excelentes perspectivas de cara al futuro con un potencial de 10,5 millones de personas y una tasa de crecimiento anual del $6,1 \%$, contexto en el cual la Asociación Nacional de Universidades e Instituciones de Educación Superior (ANUIES, 2014) tiene el firme objetivo de promover que se eleve la cobertura de la educación superior en al menos un $48 \%$ en México para el año 2020.

Los estudios que desarrollan los profesionales de la contaduría abarcan la teoría y práctica del desarrollo y mantenimiento, auditoría y registro de transacciones financieras de las empresas o individuos. Los programas de estudio que forman a los profesionales de la contaduría en gran medida 
manifiestan contenidos relacionados con la interpretación, evaluación y preparación de estados financieros para el buen uso de las empresas y contribuir a la toma de decisiones en temáticas que consideran aspectos de análisis tributario, auditoría, contabilidad administrativa, contabilidad financiera, contabilidad fiscal, contaduría pública, contaduría privada, contribuciones y administración fiscal, de acuerdo con el Instituto Nacional de Estadística y Geografía (INEGI, 2011).

Tabla 3. Indicadores estratégicos del campo profesional de la contaduría en el Estado de Puebla (estimaciones a 2013)

\begin{tabular}{|c|c|}
\hline Indicador & Valor/ponderación \\
\hline $\begin{array}{l}\text { Personas ocupadas, periodo } \\
\text { 2012-2013, que estudiaron alguna } \\
\text { licenciatura relacionada con } \\
\text { contaduría }\end{array}$ & $\begin{array}{l}\text {-En 2012: 21,873 profesionistas } \\
\text {-En 2013: 24,364 profesionistas }\end{array}$ \\
\hline $\begin{array}{l}\text { Cinco principales ocupaciones de las } \\
\text { personas ocupadas que estudiaron } \\
\text { alguna licenciatura relacionada con } \\
\text { contaduría }\end{array}$ & $\begin{array}{l}\text {-Contadores, auditores, especialistas en } \\
\text { finanzas y en temas económicos: } 47 \% \\
\text {-Auxiliares en administración, contabilidad y } \\
\text { finanzas: } 8 \% \text { : } \\
\text {-Actividades secretariales, taquígrafos, } \\
\text { capturistas de datos, y operadores de } \\
\text { máquinas de oficinas: } 8 \% \\
\text {-Diversas actividades entre las cuales se } \\
\text { considera el emprendimiento: } 40 \% \text { : }\end{array}$ \\
\hline $\begin{array}{l}\text { Ingreso mensual promedio de las } \\
\text { personas ocupadas que estudiaron } \\
\text { alguna licenciatura relacionada con } \\
\text { contaduría }\end{array}$ & $\begin{array}{l}\text {-Primer nivel, menores de } 26 \text { años o recién } \\
\text { egresados: en promedio ganan } \$ 5,318 \\
\text { mensuales } \\
\text {-Segundo nivel, mayores de } 26 \text { años o } \\
\text { egresados con experiencia: en promedio } \\
\text { ganan } \$ 8,463 \text { mensuales. }\end{array}$ \\
\hline $\begin{array}{l}\text { Género de las personas ocupadas } \\
\text { que estudiaron alguna licenciatura } \\
\text { relacionada con contaduría }\end{array}$ & $50 \%$ mujeres y $50 \%$ hombres \\
\hline
\end{tabular}

Fuente: elaboración propia con datos del Observatorio Laboral de la Secretaría del Trabajo y Previsión Social (2014). 
En cuanto a la calidad de la educación superior en México, el Estado de Puebla se posiciona en un lugar privilegiado en el nivel académico de sus instituciones de educación superior (IES) en toda Latinoamérica, en virtud de que el Estado de Puebla cuenta fehacientemente con alto prestigio de calidad educativa universitaria y varias de las mejores 300 IES en Latinoamérica se ubican en específico en la Ciudad de Puebla (QS University Rankings, 2013). Puebla, junto con las entidades federativas del Distrito Federal, Estado de México, Nuevo León y Jalisco, brindan ofertas académicas de gran calidad a nivel Latinoamérica acorde a los siguientes indicadores: reputación académica, reputación del empleador, calidad de los estudiantes, documentos de investigación citados, documentos de investigación por facultad, personal académico con grado de Doctorado, $y$ el impacto a través de internet.

En educación superior Puebla representa un importante centro de formación universitaria dado que, entre otras características, hasta el año 2012 contó con el 5,3\% del total nacional de catedráticos, atendiendo al $6 \%$ del total nacional de matrícula y ofertando alrededor del $8 \%$ del total nacional de programas académicos en pregrado y posgrado, expidiendo anualmente alrededor del 4,9\% del total nacional de cédulas profesionales. Y en el aspecto de investigación, el Estado de Puebla posee alrededor del 3,7 \% del total nacional de catedráticos pertenecientes al Sistema Nacional de Investigadores, datos que aporta el Estudio Comparativo de las Universidades Mexicanas (EXECUM, 2013).

Según datos del Sistema Nacional de Información Estadística Educativa (SEP, 2014) de la Secretaría de Educación Pública, el sistema educativo de Puebla cuenta con las estadísticas, planteadas en la tabla 4, por el periodo 2008-2013.

Analizando la información anterior, se observa que en los últimos años la demanda de educación superior en Puebla tuvo un crecimiento sostenido que representó un incremento de 31,20\% acumulado durante el periodo 2008-2013 y esto representó un promedio anual de crecimiento de 5,58 \%. Gracias a esta expansión de la matrícula en educación superior en Puebla en 
el periodo de referencia se explica que la cobertura de educación superior a nivel licenciatura haya alcanzado un porcentaje equivalente a $31,7 \%$ de los jóvenes de entre 19 a 23 años en el periodo 2012-2013, muy superior al 24,7 $\%$ de cobertura existente cinco años atrás, con lo cual Puebla actualmente se sitúa en este indicador en línea con el objetivo de elevar la cobertura de la educación superior hasta el 48 \% para el año 2020 acorde a la meta establecida por la ANUIES.

Tabla 4. Sistema educativo a nivel superior de Puebla 2008-2013: estadísticas generales

\begin{tabular}{ccccc}
\hline Periodo & Alumnos & $\begin{array}{c}\text { \% del sistema } \\
\text { educativo } \\
\text { total }\end{array}$ & $\begin{array}{c}\% \text { de } \\
\text { deserción }\end{array}$ & $\begin{array}{c}\text { \% de cobertura } \\
\text { a nivel } \\
\text { licenciatura }\end{array}$ \\
\hline $2008-2009$ & 148,471 & $8,0 \%$ & $12,4 \%$ & $24,7 \%$ \\
\hline $2008-2009$ & 148,471 & $8,0 \%$ & $12,4 \%$ & $24,7 \%$ \\
\hline $2008-2009$ & 148,471 & $8,0 \%$ & $12,4 \%$ & $24,7 \%$ \\
\hline $2008-2009$ & 148,471 & $8,0 \%$ & $12,4 \%$ & $24,7 \%$ \\
\hline $2008-2009$ & 148,471 & $8,0 \%$ & $12,4 \%$ & $24,7 \%$ \\
\hline
\end{tabular}

Fuente: Sistema Nacional de Información Estadística Educativa (2014).

En este contexto de crecimiento sostenido de la demanda en educación superior en el país, la Licenciatura en Contaduría y Alta Dirección tiene un alto potencial de tomar beneficios de esta creciente demanda si se considera que históricamente en México las disciplinas académicas que más interesan al estudiante mexicano, a pesar de la creciente diversificación de licenciaturas emergentes, son las seis licenciaturas que tradicionalmente poseen mayor número de estudiantes: Derecho, Contaduría, Magisterio, Medicina, Computación y Sistemas, y Administración. 


\section{Análisis del campo profesional}

Acerca del campo profesional en el que se desempeñan los profesionales de la contaduría, a través de fuentes secundarias de información, se indagó en el año 2014 sobre los conocimientos, habilidades y actitudes que actualmente requieren los empleadores de los profesionistas relacionados con la Contaduría y Alta Dirección, considerando entre las empresas consultadas a Provident, Cementos Mexicanos, Bain \& Company, Cummins, y Petróleos Mexicanos, que corresponden a los sectores de banca y servicios financieros, sector industrial cementero, servicios de consultoría, fabricación de automotores, y el sector de energía y petróleo, respectivamente. De esta investigación se resumen en la tabla 5 los conocimientos, habilidades y actitudes requeridas para puestos donde el perfil deseado corresponde a Licenciados relacionados con las carreras de Contaduría y Finanzas, en funciones que abarcan responsabilidades involucradas con contraloría, planeación financiera, impuestos y área fiscal en general, contabilidad general y auditoría interna:

Tabla 5. Necesidades del mercado ocupacional relacionado con la Licenciatura en Contaduría y Alta Dirección

\begin{tabular}{|c|c|}
\hline Indicador & Valor/ponderación \\
\hline & $\begin{array}{l}\text { - En administración financiera, con énfasis en finanzas } \\
\text { corporativas. } \\
\text { - En Normas Internacionales de Información Financiera. } \\
\text { - En el manejo y revisión de impuestos directos, } \\
\text { indirectos, locales, estatales y federales. }\end{array}$ \\
\hline $\begin{array}{l}\text { En términos } \\
\text { de conocimientos }\end{array}$ & $\begin{array}{l}\text { - En aspectos de seguridad social y el crédito a la vivienda } \\
\text { de los trabajadores, así como el seguro de retiro. } \\
\text { - En materia laboral, mercantil y de todo tipo de } \\
\text { prácticas. } \\
\text { - En análisis de control interno y auditorías. } \\
\text { - En sistemas integrales Enterprise Resource Planning y } \\
\text { software de gestión empresarial. }\end{array}$ \\
\hline
\end{tabular}




\begin{tabular}{|c|c|}
\hline Indicador & Valor/ponderación \\
\hline $\begin{array}{l}\text { En términos } \\
\text { de habilidades }\end{array}$ & $\begin{array}{l}\text { - Para coordinar la emisión, calidad y entrega oportuna } \\
\text { de estados financieros. } \\
\text { - Para asegurar el cumplimiento de políticas, } \\
\text { procedimientos y regulaciones tanto interna como } \\
\text { externamente. } \\
\text { - Para diseñar la estrategia contable y financiera de corto } \\
\text { y largo plazo. } \\
\text { - Para analizar, interpretar e informar los resultados de la } \\
\text { entidad tanto a los inversores como a las autoridades. } \\
\text { - Para crear canales de comunicación interna y externa } \\
\text { con objeto de brindar apoyo y asesoría a las diferentes } \\
\text { áreas. } \\
\text { - Para dirigir, asesorar y propiciar el desarrollo del } \\
\text { personal. } \\
\text { - Para administrar adecuadamente los recursos y generar } \\
\text { ahorros. } \\
\text { - Para crear ambientes de trabajo cordiales, así como } \\
\text { identificar áreas de mejora y atender a los auditores } \\
\text { externos. }\end{array}$ \\
\hline $\begin{array}{l}\text { En términos } \\
\text { de actitudes }\end{array}$ & $\begin{array}{l}\text { - Excelente comunicación } \\
\text { - Organización y metodología } \\
\text { - Dominio del estrés } \\
\text { - Pensamiento estratégico } \\
\text { - Vocación de optimizar los recursos } \\
\text { - Orientación a resultados } \\
\text { - Actitud de negociación y resolución de problemas }\end{array}$ \\
\hline
\end{tabular}

Fuente: elaboración propia con datos de la Firma de Recursos Humanos Michael Page (2014).

También se realizó una consulta a través de diversas reuniones en Academia, donde se tuvo la oportunidad de congregar a talentosos egresados en Contaduría de nuestra Institución, y que actualmente se desempeñan 
exitosamente en firmas de reconocido prestigio en materia de servicios profesionales de contadores independientes a nivel local e internacional, egresados que se desempeñan en la iniciativa pública y en la privada, en calidad de empleadores, y especialistas en contaduría; indagando acerca de las características que deben poseer los egresados en Contaduría para desempeñarse en la oferta laboral que solicitan. En este contexto se identificaron los conocimientos, habilidades, y actitudes y valores que deben poseer los profesionales de la contaduría en la actualidad.

En consecuencia, con respecto a los rasgos de los egresados en Contaduría que requiere el mercado laboral en materia de conocimientos, se destacan los siguientes:

- Conocimientos en diseño de sistemas de información financiera.

- Capacidad de establecer mecanismos de control interno en todos los niveles de la operación.

- Capacidad de presentar y analizar todo tipo de informes tanto de carácter financiero como administrativo.

- Dominio y aplicación de la legislación tributaria.

- Aplicación de herramientas de contabilidad administrativa y de gestión con énfasis en costos.

- Conocimientos de ética en las empresas y a nivel profesional independiente.

- Conocimientos en tecnologías de información y en software de gestión contable y de operaciones en su conjunto.

Con respecto a los rasgos de los egresados en Contaduría que requiere el mercado laboral en materia de habilidades, en este proceso se identificaron:

- Habilidad para desarrollar planeación, organización, dirección y control en el desempeño de sus actividades laborales. 
- Habilidad de toma de decisiones efectivas y con asertividad.

- Habilidad para aplicar creativamente los conocimientos y capacidades.

- Habilidad para ejercer liderazgo y llevar a cabo negociaciones.

- Habilidad para promover el trabajo en equipo.

- Habilidad para investigar, desarrollar y difundir los conocimientos.

- Habilidad para comunicarse eficientemente de manera oral y escrita, incluso en un idioma extranjero.

Con respecto a los rasgos de los egresados en Contaduría que requiere el mercado laboral en aspecto de actitudes o valores, se identificaron:

- Responsabilidad: reconocer y aceptar las consecuencias de sus actos.

- Compromiso: atender, dar soluciones y respuestas a las obligaciones contraídas.

- Solidaridad: adhesión a la causa de otros.

- Respeto: consideración o deferencia hacia los demás.

- Tolerancia: respetar ideas y creencias de los demás.

- Justicia: reconocer a cada quien lo que le corresponde o pertenece.

- Honestidad: actuación con espíritu de bien común y rectitud.

- Veracidad: expresar claramente, con certeza, realidad y sinceridad lo que se piensa y sabe.

- Integridad: relacionar al mismo tiempo la justicia, la veracidad y la honestidad.

- Libertad: ejercer su voluntad. 
Para profundizar más en el análisis del campo profesional también se indagó acerca de las competencias técnicas requeridas a nivel internacional por los profesionistas de la contaduría desde la perspectiva calificada del Consejo Internacional de Estándares de Educación Contable (IAESB, por sus siglas en inglés), organismo internacional perteneciente a la Federación Internacional de Contadores, cuyo objetivo es fortalecer el desempeño profesional de la profesión contable a través de estrategias de aplicación en el proceso educativo. Este Consejo ha diseñado una serie de normas que promueven la mejora del nivel de competencia de los profesionales contables durante sus estudios profesionales y que les permitan adquirir óptimas competencias técnicas, habilidades profesionales, valores, principios éticos y actitudes (IASBEB, 2014).

En este contexto se identificaron las siguientes competencias técnicas que deben desarrollar los estudiantes de contaduría en el ámbito mundial acorde a once áreas de conocimiento:

\section{Competencias técnicas en materia de contabilidad} e información financiera:

- Aplicar las Normas Internacionales de Información Financiera (NIIF) o cualquier otra norma aplicable para transacciones u otros eventos.

- Elaborar e interpretar estados financieros incluyendo estados financieros consolidados de acuerdo con los estándares internacionales $\mathrm{u}$ otros que se consideren de importancia.

- Interpretar reportes que no incluyan información financiera.

Competencias técnicas en materia de contabilidad administrativa y de gestión: 
- Aplicar técnicas de apoyo a la toma de decisiones de gestión considerando aspectos de costeo de productos, análisis de varianza, la gestión de inventarios, presupuestos y pronósticos.

- Preparar reportes que soporten la toma de decisiones de gestión, incluyendo reportes que se enfoquen en la planeación y elaboración de presupuestos, costos de gestión, control de calidad, medición del desempeño y benchmarking.

- Evaluar el desempeño de los productos y segmentos de negocio.

Competencias técnicas en materia de gestión financiera:

- Analizar la situación financiera actual y futura de una organización utilizando técnicas como el análisis de razones financieras, análisis de tendencias y análisis de flujo de efectivo.

- Determinar el costo de capital de una organización de tal manera que se permita evaluar las distintas fuentes de financiamiento disponibles para la organización.

- Aplicar técnicas de presupuestos de capital en la evaluación de las decisiones de inversión de capital.

Competencias técnicas en materia de contribuciones y obligaciones fiscales:

- Dominio de los requisitos nacionales de cumplimiento fiscal y de presentación de información al respecto.

- Preparar cálculos de impuestos directos e indirectos para individuos y organizaciones.

- Analizar aspectos fiscales relacionados con tributación internacional que puedan implicar evitar doble imposición y aspectos en materia de precios de transferencia. 
Competencias técnicas en materia de auditoría de estados financieros:

- Aplicar métodos cuantitativos y estándares de auditoría pertinentes a la entidad, incluyendo las leyes y reglamentos aplicables a la auditoría de estados financieros.

- Evaluar los riesgos de errores en los estados financieros y considerar el impacto que tienen en la estrategia de auditoría.

- Identificar los elementos clave de los contratos de aseguramiento y estándares aplicables que son relevantes para este tipo de compromisos.

Competencias técnicas en materia de control interno, gestión de riesgos y gobierno corporativo:

- Aplicar los principios de buen gobierno, incluyendo los derechos y las responsabilidades de los propietarios, los inversionistas y aquellos encargados del gobierno corporativo; considerando en todo momento los requisitos de transparencia en la divulgación de información.

- Analizar los riesgos y oportunidades de una organización usando un marco de gestión de riesgos adecuado.

- Analizar los componentes del control interno relacionados con la información financiera.

Competencias técnicas en materia de leyes y reglamentos:

- Dominio de las leyes y reglamentos que rigen las distintas formas de personas jurídicas. 
- Dominio de las leyes y reglamentos aplicables al entorno en el que operan los contadores profesionales y las entidades en las cuales desarrollan su actividad.

Competencias técnicas en materia de tecnologías de la información:

- Evaluar la eficiencia de los controles basados en tecnologías de información que utilizan las entidades.

- Aplicar las tecnologías de información para el análisis de datos y toma de decisiones.

- Usar la tecnología de la información para facilitar el análisis de negocios.

Competencias técnicas en materia de globalización y entorno de los negocios:

- Describir el entorno en el que opera la organización considerando las fuerzas económicas, jurídicas, políticas, sociales, tecnológicas, internacionales y culturales.

- Analizar los aspectos del entorno global que afectan al comercio y finanzas internacionales.

- Identificar las características de la globalización incluyendo el papel de las multinacionales, el comercio electrónico y los mercados emergentes.

Competencias técnicas en materia de economía:

- Entender los principios fundamentales de microeconomía y macroeconomía. 
- Interpretar el efecto de los cambios en los indicadores macroeconómicos y su impacto en la actividad empresarial.

- Identificar los diferentes tipos de estructuras de mercado como competencia perfecta, competencia monopolística, monopolio y oligopolio.

Competencias técnicas en materia de administración estratégica:

- Conocer las diferentes formas en que las organizaciones pueden ser diseñadas y estructuradas.

- Saber explicar el propósito y la importancia de los diferentes tipos de áreas funcionales y operativas dentro de las organizaciones.

- Analizar los factores externos e internos que pueden influir en la estrategia de una organización.

- Explicar los procesos que pueden utilizarse para aplicar la estrategia de una organización.

- Conocer cómo las teorías de comportamiento organizacional pueden ser usadas para mejorar el desempeño de la persona, los equipos y la organización.

A su vez, acorde a la fuente de información consultada en este proceso, se identificaron las habilidades profesionales, que se sugiere, deben desarrollar los estudiantes de contaduría a nivel mundial acorde a cuatro criterios.

\section{Habilidades profesionales de orden mental:}

- Evaluar información procedente de diversas fuentes y perspectivas, a través de la investigación, el análisis y la integración.

- Aplicar el juicio profesional incluyendo la identificación y evaluación de alternativas para llegar a conclusiones bien razonadas que deben estar basadas en hechos y circunstancias de importancia. 
- Identificar las situaciones en las cuales se considere apropiado consultar con especialistas en temas específicos, con objeto de arribar a la solución óptima de problemas y fortalecer el alcance de soluciones.

- Aplicar el correcto razonamiento, análisis crítico y pensamiento innovador para la solución de problemas.

Habilidades profesionales de orden interpersonal y comunicativa:

- Mantener actitud cooperativa y de trabajo para alcanzar metas organizacionales.

- Comunicar de forma clara y concisa al presentar, discutir e informar situaciones formales e informales, sea de manera oral o escrita.

- Demostrar conocimiento sobre las diferencias culturales y de idioma en diversos contextos.

- Aplicar habilidades de negociación para el alcance de soluciones y acuerdos, lo que incluye la habilidad de aplicar técnicas de entrevista efectiva.

- Presentar ideas e influir en otros para proporcionar apoyo y compromiso.

Habilidades profesionales de orden personal:

- Compromiso permanente con el aprendizaje.

- Aplicar escepticismo profesional y evaluar críticamente toda información.

- Administrar tiempo y recursos para el logro de compromisos profesionales.

- Anticipar desafíos y planificar soluciones. 
- Tener mente abierta ante nuevas oportunidades.

Habilidades profesionales de orden organizacional:

- Responsabilidad para cumplir las actividades encomendadas con los plazos acordados.

- Supervisar el trabajo propio y el de otros para determinar si cumple con los estándares de calidad de la organización.

- Aplicar habilidades de gestión para motivar y ayudar al desarrollo de otros.

- Aplicar habilidades de delegación para distribuir trabajos.

- Aplicar habilidades de liderazgo para influir en el trabajo de otros y su dirección hacia las metas organizacionales.

- Aplicar apropiadamente las tecnologías de la información para incrementar la eficiencia y eficacia en la toma de decisiones.

Por otra parte, con respecto a los valores, ética y actitudes profesionales que deben desarrollar los estudiantes de contaduría a nivel mundial se identificaron acorde a dos criterios.

Valores, ética y actitudes profesionales en términos de escepticismo y juicio profesional:

- Aplicar cuestionamiento crítico para evaluar la información financiera y otros datos relevantes.

- Identificar y evaluar las alternativas razonables para llegar a conclusiones razonadas basadas en todos los hechos y circunstancias relevantes.

Valores, ética y actitudes profesionales en términos de principios éticos:

- Conocer la naturaleza de la ética. 
- Discernir las ventajas y desventajas de las reglas y principios basados en los enfoques éticos.

- Analizar rutas alternativas de acción y determinar las consecuencias éticas de estas.

- Aplicar los principios éticos fundamentales de integridad, objetividad, confidencialidad y debido cuidado profesional.

- Aplicar estándares éticos pertinentes en el cumplimiento de estándares profesionales y legales requeridos.

\section{Las tendencias de la profesión contable}

Históricamente la actividad pública y social de la Licenciatura en Contaduría y Alta Dirección tiene dos facetas básicas. La primera, distingue la necesidad social que debe proveer la profesión de la contaduría como el ineludible requerimiento que toda entidad, persona física o moral, tiene de identificar y entender su propia situación financiera a través de información oportuna y veraz, que al mismo tiempo permita la toma de decisiones administrativas, y facilite el cumplimiento de las obligaciones de todo tipo, además de servir esta información para controlar los bienes, derechos y patrimonio. La segunda faceta de la necesidad social a satisfacer por la profesión de la contaduría se sustenta en el manejo de información financiera, para situarse intrínsecamente relacionada en el campo de la administración financiera de las entidades, lo que involucra diversas actividades con objeto de facilitar la toma de decisiones para planear, organizar, dirigir y ejercer control sobre el origen de los recursos o fuentes de financiamiento y la aplicación de estas fuentes en diversas inversiones que generen valor a la entidad.

En adición a lo anterior, de cara al futuro, la proyección de la profesión de la contaduría a nivel mundial considera las siguientes tendencias (Federación Internacional de Contadores, 2010):

- Los cambios en el ambiente global tendrán consecuencias directas para la profesión contable: por lo cual temas referentes a la economía, 
el medio ambiente, la empresa sustentable y la sociedad constituyen guías significativas para adaptarse a los cambios y aprovechar las fuentes de oportunidad.

- En las próximas décadas los profesionales de la contaduría deberán enfrentar el cambio y aprovechar las nuevas oportunidades: en el futuro próximo un importante desafío será el contar con la capacidad de desarrollo de las habilidades existentes y al mismo tiempo incorporar las nuevas habilidades requeridas para reportar y evaluar el desempeño financiero y no financiero de cualquier tipo de entidad económica.

- Existe una importante tendencia tanto en el incremento en la audiencia como en el tipo de reportes a emitir, en un contexto que requiere cada vez mayor responsabilidad social en el funcionamiento de la economía: es una realidad que actualmente el requerimiento de certificaciones sea más palpable en los profesionistas de la contaduría a nivel mundial. Lo que requiere la necesidad de reconsiderar las expectativas tanto de los profesionistas en la materia, como de sus clientes, empleados, las comunidades, los mercados financieros, las entidades gubernamentales y cualquier parte interesada que interviene en el sistema contable en su conjunto.

- Se reconoce una tendencia en el aumento del carácter normativo de la información financiera y en las exigencias de cumplimiento de aspectos contables: aspectos básicos como que la contabilidad financiera tiende a ser de carácter normativo u obligatorio, por lo cual resulta la responsabilidad de cualquier entidad de poseer un sistema contable que genere información para establecer la veracidad y confiabilidad de la información que este sistema genera y que es indispensable para efectos fiscales, así como para verificar que la entidad desarrolla las prácticas administrativas y comerciales acorde a la legalidad.

- Se vislumbra mayor convergencia entre la emisión de reportes financieros para uso interno y externo: se tiende a disminuir en la 
medida de lo posible la brecha entre la información financiera para análisis del desempeño externo como del interno, lo que requiere un sistema contable combinado capaz de servir para el registro de transacciones y la toma de decisiones.

- Fortalecimiento del gobierno corporativo en las entidades: los profesionales de la contaduría dentro de sus actividades enfocadas a la alta dirección deben proporcionar en primera instancia información financiera y las respectivas recomendaciones a los consejos de administración u organismos análogos en cada tipo de entidad, situación que representa un elemento vital dentro del esquema de gobierno corporativo con miras a mantener un ambiente de transparencia y conducta ética dentro de las organizaciones. En este contexto, los profesionales de la contaduría representarán un factor clave en el desarrollo e implementación de los marcos regulatorios para guiar el gobierno corporativo de las entidades.

- Tendencia a reportar cuestiones referentes al impacto social y ambiental de las entidades: el término "sustentabilidad" ha ido en ascenso en su uso y aplicación dentro de las organizaciones, concepto que intrínsecamente se refiere a la permanencia y estabilidad de la entidad a largo plazo. En este sentido, los profesionales de la contaduría deben desarrollar nuevas habilidades para realizar la medición de cualquier elemento susceptible de ser valuado y contabilizado, dado que las transformaciones sociales y medio ambientales tenderán a ser la guía en el diseño de nuevos indicadores de desempeño y sustentabilidad económica y financiera. Lo que representa un reto para los profesionistas de la contaduría dado que deberán desarrollar nuevas formas de reportar y medir la creación de valor económico teniendo absoluta sensibilidad del cuidado del medio ambiente y del impacto social de las actividades de la entidad, en donde asuntos como la medición y revelación de información relativa al uso de carbono por parte de empresa y gobierno, así como el impacto de la actividad de la entidad en los ecosistemas y la biodiversidad deberá 
desarrollarse en el futuro próximo, contexto en el que los conceptos "economía verde", "contabilidad verde" y "finanzas verdes" tendrán una amplia popularidad en próximas décadas haciendo alusión a un modelo económico basado en el cuidado del medio ambiente y propiciando un desarrollo sustentable.

En consecuencia, el profesional de la contaduría debe ser capaz de ayudar a las entidades en el fortalecimiento de los controles y la eficiente gestión de riesgos, en la tarea de contribuir al desarrollo sustentable a largo plazo y también contribuir al desarrollo competitivo del país.

\section{Sustento disciplinar de la profesión}

Muchos factores han impactado durante los últimos años el funcionamiento del desarrollo de la disciplina de la contaduría: escándalos financieros, crisis financieras, el avance de las tecnologías, las reformas estructurales impulsadas desde organismos internacionales, la convergencia en la normatividad contable, los cambios en la demanda de servicios que la sociedad exige a los profesionistas contables, entre otros. Esto ha resultado en que históricamente el profesional contable tradicional dejó de ser desde hace mucho tiempo un referente de la teneduría de libros para convertirse en un profesional con enfoque financiero-directivo, brindando un servicio de alta generación de valor para las empresas en las que labora de manera subordinada y para las que brinda asesoría de manera independiente.

El desarrollo de los mercados internacionales, en los aspectos comercial y financiero; la actuación de empresas multinacionales y el comportamiento de los inversores, han contribuido al proceso de la globalización internacional en el que se encuentran actualmente inmersos todos los sectores de la actividad económica. Este proceso de globalización amplió el ámbito de actuación de los distintos agentes económicos, lo que ha incidido en que la información contable haya traspasado las fronteras nacionales, siendo la información que genera el sistema contable en su conjunto de interés dentro y fuera país. 
En consecuencia, la información financiera que genera la profesión contable representa un medio de comunicación estratégico en la gestión de las empresas. Lenguaje que también es útil para los distintos interesados en su funcionamiento y que involucra a empleados, inversores, accionistas, dependencias gubernamentales, clientes y acreedores, así como a investigadores, académicos y a la sociedad en general. En este contexto, todos los elementos que involucran al sistema de la profesión contable tienden a evolucionar rápidamente en diversas aristas, en lo referente a los diversos métodos de reconocimiento, valoración y divulgación de información financiera, en la adaptación al entorno y las nuevas necesidades informativas de la propia empresa y otros usuarios que debe satisfacer, haciendo énfasis en los usuarios involucrados con el sistema de recaudación fiscal.

La profesión contable involucra un lenguaje común e indispensable para la gestión de las empresas y desde sus primeras conceptualizaciones técnicas en torno a la partida doble, que datan de finales de Siglo XV por Fray Luca Bartolomeo de Paccioli, se reveló como una técnica que debería ser mundialmente reconocida y aplicada, que actualmente representa un lenguaje universal en los negocios.

La profesión contable involucra inherentemente el dominio y conocimiento de factores legales, políticos, económicos, culturales y profesionales, que en su conjunto conforman el sistema contable en el cual se desarrollan las entidades. Incluso la profesión contable busca mediante la aplicación de métodos científicos, identificar las óptimas soluciones a problemáticas específicas de las entidades.

Desde la vertiente profesional diferentes organismos e instituciones realizan constantes esfuerzos con miras a conseguir un mayor grado de comparabilidad en la información financiera que el sistema contable genera, de tal manera que permita a los agentes implicados en el uso de información contable tales como empresas, mercados de capitales y otros usuarios, comprender adecuadamente la información empresarial sea cual fuere su procedencia geográfica. Las instituciones de educación superior están conscientes de esta realidad y en los procedimientos de reformas en 
sus planes de estudios, suelen incorporar asignaturas que dan énfasis a aspectos de normatividades internacionales, de información financiera y de auditoría, así como incluir aspectos de carácter internacional relacionados con las finanzas y la internacionalización de las entidades.

En México, el sistema contable históricamente ha estado marcado por una fuerte influencia ejercida en primera instancia por Estados Unidos, que es comprensible dado el gran intercambio comercial y de inversiones que existe entre ambos países y que propicia, en consecuencia, que el sistema contable de México tenga rasgos claramente anglosajones en aspectos de generación de información financiera de las entidades y de regulación. El proceso regulador de información financiera en México es muy similar a Estados Unidos, dado que primero, la profesión se reúne y suele emitir borradores de normas de información financiera que posteriormente están sujetas a comentarios durante el periodo de auscultación, siendo a su vez enviadas a un comité ejecutivo del organismo correspondiente para su aprobación. En este sentido, la regulación contable de México en caso de no cubrir al tratamiento aplicable a determinado tipo de evento económico, deberá aplicar de manera supletoria lo que indiquen las normas internacionales del IASB.

El objetivo primordial del sistema contable a través de la profesión es proveer de información cuantitativa de forma sistémica y estructurada, expresada en unidades monetarias de las transacciones llevadas a cabo por la entidad, así como de todos los hechos económicos que la afectan. La tarea de elaboración de normativa contable es asumida en México casi con exclusividad por la profesión contable, concretamente por el Consejo Mexicano para la Investigación y el Desarrollo de Normas de Información Financiera (CINIF), y a su vez en el funcionamiento óptimo de la profesión contable participa el Instituto Mexicano de Contadores Públicos a través de sus comisiones de trabajo que involucran: comisión de apoyo a federadas; comisión de calidad de la práctica profesional; comisión de práctica externa; comisión del sector empresas; comisión gubernamental; comisión de asuntos internacionales; comisión de docencia; comisión de legislación, 
comisión de relaciones y difusión, y comisión fiscal (Instituto Mexicano de Contadores Públicos, 2014b). Este Instituto fue creado en 1923 y actualmente conglomera a más de 20,000 contadores públicos de todo México, y dentro de sus ámbitos de regulación se destaca que es el encargado de emitir la normatividad relativa al trabajo del auditor independiente, mediante normas que son utilizadas en México y en otros países.

En este entorno global, el Instituto Mexicano de Contadores Públicos pertenece a la Asociación Interamericana de Contabilidad (AIC) que agrupa a toda la profesión en todo el Continente Americano, y también pertenece a la Federación Internacional de Contadores (IFAC, por su siglas en inglés), ente que contribuye a la organización de la profesión contable a nivel mundial. En este contexto, es de destacarse que el Instituto Mexicano de Contadores Públicos define las siguientes ocho áreas de conocimiento que dentro de la profesión contable se desarrollan: auditoría, control de calidad, derecho, finanzas, contabilidad, costos, ética y fiscal (Instituto Mexicano de Contadores Públicos, 2014c). En el desarrollo de normatividades y mejores prácticas que a nivel federado el Instituto Mexicano de Contadores Públicos desarrolla, intervienen profesionales de la contaduría y representantes de los sectores empresariales, de las autoridades hacendarias, de las entidades del sector financiero y del mercado de valores.

\section{Evolución de la profesión}

La profesión contable contemporánea se desarrolla de manera vertiginosa entre la globalización de los mercados. La globalización en la forma de hacer negocios, la globalización en la manera de administrar los recursos, la globalización de los medios y tecnologías de información, y que en consecuencia incide en la globalización de las técnicas y procedimientos que la profesión desarrolla en beneficio de las entidades a las que sirve, sean de carácter público o privado.

A partir de la segunda mitad del siglo XX la práctica profesional contable ha sido testigo de muchos procesos convergentes y divergentes en lo que 
representa la actual tendencia de estandarización de normas contables a nivel mundial. Después de la Segunda Guerra Mundial, la influencia de las grandes empresas transnacionales norteamericanas permitió diseminar las prácticas de registro, valuación y presentación de transacciones en los estados financieros, acorde a los estándares estadounidenses. Posteriormente, en la década de los setentas con el déficit monetario norteamericano como consecuencia de los excesivos costos de la Guerra de Vietnam, resultó en el colapso del patrón oro-dólar que se había acordado en Bretton Woods (Ocampo, 2009).

En ese entonces también se registró en la historia el embargo petrolero, el establecimiento de la Organización de Países Exportadores de Petróleo, y una escalada en los precios internacionales del petróleo que originó un contagio inflacionario a nivel mundial donde este periodo sin precedentes en nuestra historia moderna fue detenidamente estudiado y analizado de manera técnica por expertos contables, europeos principalmente, mientras que los expertos contables norteamericanos optaron por omitir ese análisis a profundidad, lo que motivó la gran separación de las dos corrientes normativas de información financiera que a nivel internacional resaltan e impactan de manera sensible: las Normas Internacionales de Información Financiera (IFRS, por sus siglas en inglés), y los Principios de Contabilidad Generalmente Aceptados de Estados Unidos (USGAAP, por sus siglas en inglés). (Beuren, Hein y Klann, 2008).

Por un lado se promulgaron los Principios de Contabilidad Generalmente Aceptados por el Instituto Americano de Contadores Públicos Autorizados, y por el otro lado se promulgaron las Normas Internacionales de Contabilidad emitidas en ese entonces por el Comité Internacional de Normas Contables, lo que resultó en que las entidades internacionales reportaran en cada jurisdicción, con base a la normativa local con un sesgo claramente fiscalista o para fines de cumplir cabalmente las obligaciones fiscales, y adicionalmente, reportara información basada en procedimientos contables de la sede de la oficina matriz para efectos de consolidación de estados financieros y presentación para sus accionistas, 
dominando en este momento la normatividad norteamericana dado que gran parte de las mayores entidades internacionales tenían su oficina matriz en Estados Unidos.

Así transcurrieron las décadas de los setentas y ochentas, pero en los noventas cambió el escenario mundial tras la caída del Muro de Berlín y el término de la Guerra Fría, abriendo las puertas al mundo unipolar liderado por Estados Unidos, con grandes oportunidades para que sus empresas transnacionales comenzaran a realizar inversiones en países de Europa Oriental, la ex Unión Soviética y China. En ese momento el proceso de globalización se aceleró y con él la normativa contable internacional se orientaba hacia los Principios de Contabilidad Generalmente Aceptados de Estados Unidos. Sin embargo, a principios del siglo XXI con eventos tales como el 11 de septiembre de 2001 y las consecuencias macro económicas que a escala global dicho evento acarreó, se generó una crisis de dimensiones globales. Entre otros casos de deficiencias en la información contable, los más notables fueron los casos de las empresas Enron y WorldCom, lo que obligó a los cuerpos colegiados involucrados en la profesión contable de Estados Unidos y Europa a realizar una revisión exhaustiva de las deficiencias en la información financiera (Carmona y Trombetta, 2008).

Entre otras consecuencias positivas de estos hechos, nace la Ley Sarbanes Oxley. El Comité Internacional de Normas Contables se convierte ahora en Consejo Internacional de Normas Contables y establece las Normas Internacionales de Información Financiera (IFRS por sus siglas en inglés), y en consecuencia, la profesión contable a nivel mundial entiende que en un mundo globalizado e interconectado no es conveniente continuar separados normativamente, por lo cual se firma el acuerdo de Norwalk para fomentar la convergencia hacia un lenguaje contable común. Con este convenio se estableció la vinculación formal entre el Consejo de Normas Internacionales de Contabilidad que promueve las IFRS, y el Financial Accounting Standards Board (FASB) que promueve los Principios de Contabilidad Generalmente Aceptados en Estados Unidos. En el acuerdo Norwalk estos organismos plantean un programa de convergencia orientado a eliminar las diferencias 
existentes entre las normas de modelos contables norteamericanas y las internacionales (Hail, Leuz y Wysocki, 2010).

En este contexto, en 2002 nació en México el Consejo Mexicano para la Investigación y Desarrollo de Normas de Información Financiera (CINIF), encargado de emitir normas contables en el país. Desde su creación, inició un proceso de convergencia hacia la adaptación de la normatividad del Consejo de Normas Internacionales de Contabilidad sin adoptarla de manera integral, no obstante, se estableció que a partir del año 2012 la Normas Internacionales de Información Financiera se apliquen de manera obligatoria para las empresas que cotizan en la Bolsa Mexicana de Valores (González, 2010).

De cara al futuro, la crisis financiera que inició en el año 2008 y que hasta el año 2014 no se ha superado por completo, ha postergado de alguna manera el proceso de convergencia global en la normatividad contable (se espera que se resuelva durante esta segunda década del siglo XXI y décadas posteriores) en un escenario multipolar donde la influencia del dólar, el euro y el yuan o renminbi chino, como principales divisas en los intercambios e inversiones internacionales, hacen imprescindible la necesidad de establecer reglas financieras homogéneas y para lo cual lo profesionales del mundo de la contaduría deben estar preparados.

Un desafío primordial que enfrenta la profesión contable es la prevención de fraudes. Un reto que los profesionistas de la contabilidad deben asumir. Según estudios de la Asociación de Examinadores de Fraude Certificados (Association of Certified Fraud Examiners, 2012), se estima que tan solo en Latinoamérica un $75 \%$ de las empresas sufrieron esta situación durante los años 2009-2011, mientras que en 2007 esta situación se manifestaba en por lo mucho el $50 \%$ de las empresas, y en el año 2000 este porcentaje lo acontecían el $30 \%$ de las empresas latinoamericanas. En este contexto, esta Asociación señala que la incidencia del fraude se debe principalmente a los siguientes aspectos: deficiencia en los controles internos, colusión entre empleados y terceras partes, colusión entre miembros de la organización, deficiente política ética empresarial, sobrepaso de 
los controles internos por parte de la alta dirección, deficiente proceso de contratación de personal, deficiente control por parte de los directores, $y$ el riesgo inherente al negocio derivado de operaciones complejas o de alto grado de incertidumbre. Para prevenirlos, resulta trascendente proveer de habilidades, conocimientos y valores éticos a los profesionistas contables.

Entre algunas de las acciones para evitar estos ilícitos se destacan: La Ley Sarbanes-Oxley (SOX), el Modelo de Control Interno (COSO, por su siglas en inglés), las Normas para Instituciones Financieras de Basilea, los Estándares Internacionales de Auditoría y de Aseguramiento (las Normas de Auditoría Generalmente Aceptadas y las Normas Internacionales de Auditoría), y los Estándares Internacionales de Contabilidad y Finanzas (Principios de Contabilidad Generalmente Aceptados, Normas Internacionales de Información Financiera y Normas Internacionales de Contabilidad para el Sector Público).

De estas acciones derivan trascendentes conceptos que forman parte del desempeño eficiente y enfocado al bien común por parte de la profesión contable. De la Ley Sarbanex-Oxley se destaca que promueve el desarrollo del gobierno corporativo, que se refiere básicamente a la existencia de un sistema de organización cuyo fin primordial es dirigir y controlar a las entidades, definiendo claramente derechos y responsabilidades de los actores corporativos claves como accionistas, junta de directores, funcionarios de todos los niveles, gerentes y administradores, así como la intervención de otras partes interesadas en el buen funcionamiento de la entidad, lo que conlleva al establecimiento de reglas y procedimientos para la toma de decisiones; considerando también procesos para supervisar que los intereses de la entidad se cumplan y los recursos se utilicen de manera eficiente.

Del modelo COSO, se destaca la relevancia del control interno conceptualizado como el proceso continuo que realiza la entidad con el objeto de brindar seguridad razonable en la consecución de los objetivos de la entidad, considerando: la garantía en la confiabilidad de los informes financieros, la eficiencia y eficacia de las operaciones, y el cabal cumplimiento de las leyes y regulaciones aplicables a las entidades en la jurisdicción donde se 
localicen. El desarrollo de un eficiente control interno, en consecuencia, involucra la necesidad de que el profesional contable tenga la capacidad de contribuir a la seguridad razonable de la información mediante actividades de supervisión o monitoreo, de información y comunicación, actividades relacionadas directamente con el establecimiento de controles, actividades relacionadas con la evaluación de riesgos, y actividades relacionadas con propiciar que exista y se mantenga de manera continua el ambiente de control interno en las entidades.

COSO (2006) publicó una interesante guía que a través de 20 principios básicos ilustra los cinco componentes del control interno en beneficio de las entidades y a las cuales la profesión contable brinda sus servicios. En lo referente al componente de ambiente de control se contemplan siete principios básicos: la solidez en la integridad y los valores éticos; el ejercicio responsable del Consejo de Administración; la existencia de una filosofía y estilo operativo de la dirección; la existencia de una estructura administrativa que promueva el control; contar con las competencias óptimas para obtener y supervisar los reportes de información financiera; asignación de la autoridad y responsabilidad; y contar con políticas y prácticas de recursos humanos que fortalezcan el control interno.

En el componente de evaluación de riesgos se observan tres principios básicos: objetividad en el reporte de la información financiera, prevención de riesgos al reportar la información financiera, y la prevención de riesgo de fraude. En el componente de actividades de control, cuatro principios básicos: acciones de integración para abordar riesgos y lograr los objetivos de información financiera, selección y desarrollo de actividades de control considerando su costo y eficacia potencial, establecimiento de políticas y procedimientos de control acorde a las directrices de la Dirección, y uso de tecnologías de información y la implementación de su control para reportar información financiera.

En el componente de información y comunicación también se meditan cuatro principios básicos: generación y uso de información financiera pertinente en todos los niveles de la entidad, generación y uso de información 
que sirva para poner en marcha otros componentes del control interno, el diseño de una comunicación interna eficaz, y la disponibilidad de canales de comunicación externos para informar oportunamente a todas las partes interesadas externamente a la entidad, como acreedores, accionistas y entidades gubernamentales.

Finalmente, respecto al último componente del marco integrado de control interno y que se refiere a la supervisión, se contemplan dos principios básicos: evaluaciones continuas y separadas para verificar que el control interno funciona de manera correcta, y la realización de reportes periódicos de posibles deficiencias en los sistemas de control.

Con respecto a las Normas para Instituciones Financieras de Basilea, estas tienen un impacto positivo en el desempeño de la profesión contable dado que promueven la transparencia y comparabilidad de la información en un sector estratégico en el cual el profesional contable ampliamente es requerido: el sector financiero. El Comité de Basilea, que contó entre sus miembros con especialistas de México, estableció una serie de principios básicos para una supervisión bancaria efectiva, destacando (Banco de Pagos Internacionales, 2012): todo sistema eficaz de supervisión bancaria debe contar con atribuciones, objetivos y potestades claramente definidos; el supervisor bancario debe contar con independencia y procesos transparentes amparados por un marco jurídico; deben existir mecanismos de cooperación y colaboración entre leyes y regulaciones; definir la actividades permitidas a operar como bancos; establecer criterios de autorización para conceder licencias para operar bancos; definir la potestad de los supervisores bancarios para evaluar la titularidad de participaciones y control en los bancos; supervisar las adquisiciones sustanciales que realicen los bancos; realizar el desarrollo de perfil de riesgos de los bancos; desarrollar técnicas y herramientas de supervisión de los bancos considerando su importancia sistémica; la supervisión debe realizarse en una base consolidada para todo el grupo bancario; exigir que las operaciones locales de bancos extranjeros se lleven a cabo en virtud de las mismas normas que aplican a la entidades locales; garantizar que los bancos y grupos bancarios cuenten con sólidas 
políticas en materia de gobierno corporativo; verificar que los bancos cuenten con procesos de gestión de riesgos; exigir a los bancos a que cuenten con requerimientos de capital prudentes y suficientes; exigir que los bancos cuenten con adecuados sistemas de auditoría y controles internos, así como sistemas óptimos de divulgación y transparencia de información; y vigilar el adecuado proceso de gestión de riesgos de un banco y que incluye a los riesgos de crédito, los riesgos de concentración y límites de exposición a grandes riesgos, el riesgo país y de transferencia que los bancos enfrentan en sus operaciones de préstamos e inversiones internacionales, riesgo de mercado, riesgo de tasa de interés en la cartera bancaria, riesgo de liquidez $\mathrm{y}$ riesgo operacional.

Por otra parte, en relación a los Estándares Internacionales de Auditoría y de Aseguramiento (NAGA y NIA), estos inciden invariablemente en el desempeño de la profesión contable. Las NAGA fueron desarrolladas en Estados Unidos por el Instituto Americano de Contadores Públicos Certificados o American Institute of Certified Public Accountants (2014), y considera diez normas que representan una guía significativa para la profesión contable en materia de auditoría.

Las tres primeras corresponden a normas generales y requieren que la auditoría sea realizada por una o varias personas que tengan formación técnica adecuada y competencia como auditores; que en todos los asuntos concernientes a la auditoría el auditor mantenga independencia de actitud mental; el trabajo de auditoría debe ejecutarse con el debido cuidado profesional desde la planeación hasta la elaboración del informe resultante del trabajo. Las tres siguientes contemplan normas de ejecución del trabajo y necesitan que el trabajo se planeé adecuadamente y los asistentes sean supervisados rigurosamente; se debe obtener conocimiento suficiente del control interno para determinar la naturaleza, alcance y extensión de los procedimientos de auditoría; y se debe obtener evidencia suficiente y competente con el fin de tener bases razonables para emitir opinión al respecto de los estados financieros auditados. Finalmente, las otras cuatro normas corresponden a normas de información y requieren que el informe del 
auditor manifieste si los estados financieros están presentados acorde a los principios de contabilidad o reglas de información financiera aplicables a la entidad; especificar en el informe las circunstancias en que los principios contables o las normas de información financiera no se observaron consistentemente con respecto al periodo anterior; manifestar si las revelaciones informativas de los estados financieros se consideran razonablemente adecuadas; y expresar en el informe de auditoría una opinión referente a los estados financieros tomados en su conjunto o una aclaración si es que no puede expresarse esta opinión.

En consecuencia, las Normas de Auditoría Generalmente Aceptadas hacen énfasis en las cualidades personales que el auditor debe poseer: contar con capacitación técnica adecuada y competencia en el desempeño de la profesión contable y de auditoría; tener actitud mental independiente; contar el debido cuidado profesional; desarrollar planeación y supervisión adecuadas; poseer absoluta comprensión del control interno; obtener evidencia suficiente y competente.

Por su parte, las NIA, son estándares que inciden en la profesión contable dado que intentan regular a nivel mundial el ejercicio de la actividad de auditoría, para lo cual requieren ser aplicadas en la auditoría de estados financieros y en los casos de otros servicios relacionados, de tal manera que la auditoría asegure de manera razonable que las entidades implementen las normas contables y financieras correspondientes. Estas normas internacionales son emitidas por la Federación Internacional de Contadores (2014), que a su vez emite las Normas Internacionales para Trabajos de Atestiguamiento; las Normas Internacionales sobre Control de Calidad, las Normas Internacionales sobre Compromisos de Revisión; y las Normas Internacionales sobre Servicios Relacionados.

Por su parte, los Estándares Internacionales de Contabilidad y Finanzas (PCGA, NIIF, y NICSP) son fundamentales en el desempeño de la profesión contable. A nivel internacional representan otra medida para prevenir fraudes y armonizar el lenguaje global de los negocios mediante los tecnicismos contables y financieros. En el ámbito internacional y que incide de manera 
sustancial en México, existen dos organismos que influyen de manera notable a través de sus normativas para elaboración de estados financieros. El primero es de origen norteamericano y es el Consejo de Normas de Contabilidad Financiera (FASB, por sus siglas en inglés); y el segundo, de origen europeo, es el Consejo de Normas Internacionales de Contabilidad.

El FASB tiene trascendencia por ser la normativa reconocida por la Comisión de Bolsa y Valores de Estados Unidos (SEC, por sus siglas en inglés), que conglomera al mercado de capitales más grande del mundo y que corresponde a un socio comercial estratégico y de gran influencia para México, por lo cual estos pronunciamientos no deben ser desconocidos por el profesionista contable mexicano. De manera general los Principios de Contabilidad Generalmente Aceptados emitidos por el FASB se refieren a: equidad, entidad, bienes económicos, unidad de medida, empresa en marcha, valuación al costo, periodo contable, devengo, objetividad, realización, prudencia, uniformidad, materialidad, y exposición (FASB, 2014).

Por su parte, también de manera trascendente en el desarrollo profesional en México son importantes las NIIF, destacando que a partir del año 2012 se aplican de manera obligatoria para las empresas que cotizan en la Bolsa Mexicana de Valores, como parte de la convergencia de nuestro país hacia la normatividad internacional. Estas normas internacionales son emitidas por el Consejo de Normas Internacionales de Contabilidad a través de la Fundación IFRS (IFRS Foundation, 2014) y este organismo representa la mayor autoridad en principios y normas de información financiera a nivel mundial, con objeto de desarrollar un conjunto de normas de información financiera, de alta calidad y que sean de manera comprensible para propósitos de elaboración de estados financieros con estándares internacionales. México es uno de los países de América que ya permite el uso de Normas Internacionales de Información Financiera junto con otros 130 a nivel mundial, por lo cual la convergencia a nivel internacional en materia de información financiera es de relevante consideración en el desempeño de la profesión contable mexicana. 
De la normatividad internacional es de destacar que se contempla un apartado especial para Normas Internacionales de Información Financiera para Pequeñas y Medianas Empresas (NIIF para Pymes), que fueron emitidas en el 2009 y es importante su conocimiento dado que se estima a nivel mundial que las Pymes encarnan un importante porcentaje del sector empresarial internacional, y sin duda representa un alto porcentaje del sector empresarial de nuestro país. Por su parte, las NICSP representan normas generales de información financiera de alta calidad para ser utilizadas en las entidades del sector público como gobiernos nacionales, regionales, locales, y entidades gubernamentales relacionadas como agencias de gobierno y empresas estatales. Estas normas son desarrolladas por la Federación Internacional de Contadores a través de su Consejo de Normas Internacionales del Sector Público.

Por otra parte en el aspecto impositivo y con impacto en la profesión de la contaduría, a finales de 2013 se desarrolló y autorizó en México, un paquete económico de trascendencia en línea con el compromiso de la administración del presidente Enrique Peña Nieto de fomentar la estabilidad económica del país ante la perspectiva de un entorno económico y financiero complicado tanto a nivel nacional como internacional (Cámara de Diputados, 2014). Este paquete económico pretende fortalecer las finanzas públicas en los tres órdenes de gobierno del país durante los próximos años, y que permita incrementar el gasto e inversión del gobierno en materia de infraestructura, seguridad social, y de manera general, fomentar un desarrollo incluyente y sostenido en el país. El paquete económico dentro de la exposición de motivos resaltó entre otras cuestiones, el reconocimiento de que hasta ese momento la estructura del sistema impositivo en México había sido considerada compleja y onerosa, lo que genera que los contribuyentes destinen grandes esfuerzos y costos para cumplir sus obligaciones fiscales, en un contexto en el cual la complejidad en el cumplimiento de pago de impuestos y de obligaciones fiscales resulta perjudicial para los empresarios mexicanos. Por tanto, dentro de las reformas fiscales que el paquete económico 2014 contempló se destacan las siguientes: 
- En materia de Impuesto Sobre la Renta (ISR): mayor facilidad para presentar vía internet declaraciones de pago y contribuciones, incluyendo las declaraciones informativas; permitir la transferencia electrónica de fondos a favor de la Tesorería de la Federación como medio de pago de contribuciones; simplificar el proceso de los requisitos que deben tener los comprobantes fiscales; y la eliminación de regímenes de recaudación para pequeños contribuyentes y régimen intermedio, creando a cambio, un nuevo régimen fiscal denominado de "incorporación".

- En materia de Impuesto Empresarial a Tasa Única (IETU): este se eliminó para disminuir en gran medida la complejidad en el pago y determinación del impuesto empresarial.

- En materia de Impuestos a los Depósitos en Efectivo (IDE): también se elimina para efectos de simplificar el impuesto empresarial, de tal manera que el impuesto a las empresas queda simplificado de los tres impuestos isr, ietu, ide, a uno, el isr, eliminando los otros dos considerados impuestos de control.

- En materia del Impuesto al Valor Agregado (IVA): se elimina el tratamiento de $11 \%$ en la región fronteriza y se homologa a la tasa general del $16 \%$. En este contexto, México se alinea a estándares internacionales dado que era el único país a nivel mundial en aplicar una tasa distinta de IVA en la región fronteriza.

- En materia del Impuesto Especial sobre Producción y Servicios: de manera general se autorizó un incremento de tasas a diversos productos destacando, entre otros, a las bebidas saborizadas con azúcares añadidas y bebidas alcohólicas y cervezas, así como establecer impuestos ambientales con objeto de desincentivar el deterioro del medio ambiente al influir estos impuestos directamente en la reducción gradual de emisiones de bióxido de carbono a la atmósfera, emisiones que son las que principalmente inciden en el calentamiento global del planeta. 
- Con respecto al Código Fiscal de la Federación: se realizaron diversas reformas para evitar la evasión y elusión fiscal por los contribuyentes, para lo cual las autoridades fiscales tienen la posibilidad de determinar un crédito fiscal al contribuyente si detectan en ellos prácticas u operaciones anormales y que carezcan de racionalidad de negocios; se fortalecen medidas contra contribuyentes defraudadores; se avanza en la simplificación administrativa del sistema tributario mexicano; se facilitan las opciones de formas de pago de contribuciones; se fortalece el concepto de responsabilidad solidaria para dar mayor certeza jurídica a los socios o accionistas de las entidades; se reglamenta la obligación de reportar la contabilidad por internet mediante sistemas informáticos determinados por la autoridad; el establecimiento de nuevas obligaciones en materia de uso de comprobantes fiscales digitales por internet; así como el establecimiento de la posibilidad de efectuar "revisiones electrónicas" por parte de la autoridad a los contribuyentes.

\section{Vinculación de la profesión contable con otras disciplinas}

En los Congresos de Investigación relacionados con el análisis y exposición de temas de relevancia en la actualidad en el mundo de la contaduría, suelen abordarse, entre otros, los siguientes temas que son importante investigar constantemente para fortalecer y perfeccionar la profesión contable en beneficio de la sociedad: finanzas públicas y corporativas, gobierno corporativo, estándares internacionales en materia de información financiera, auditoría, informes de sostenibilidad, responsabilidad social empresarial, control interno, tecnologías de información, prevención de lavado de dinero $\mathrm{y}$ de fraude, $\mathrm{y}$ temas relacionados con el mercado de capitales.

De manera específica, por ejemplo, en la Trigésima Conferencia Interamericana de Contabilidad (2013), organizada por la Asociación Interamericana de Contabilidad (AIC) cuyo objetivo es reunir y organizar a toda la profesión contable de todo el Continente Americano con objeto 
de fomentar la mejora constante en la calidad profesional de los contadores así como sus conocimientos y deberes sociales, las áreas de investigación destacadas fueron las que se pueden observar en la tabla 6 .

Tabla 6. Áreas de investigación de relevancia en la actualidad en el entorno de la profesión contable

Áreas generales

\begin{tabular}{ll}
\hline Investigación contable & $\begin{array}{l}\text { Posibilidad práctica de una investigación contable } \\
\text { empírica y normativa; problemas y experiencias en la } \\
\text { adopción por primera vez de las Normas Internacionales } \\
\text { de Información Financiera en los países de América; y } \\
\text { la contabilidad ambiental: reconocimiento, medición } \\
\text { y comunicación de la actuación ambiental de las } \\
\text { entidades. }\end{array}$ \\
\hline Normas y prácticas de & $\begin{array}{l}\text { Enfoque de riesgo y determinación de materialidad en } \\
\text { auditoría de estados financieros; control de calidad de } \\
\text { auditoría } \\
\text { servicio intermedio entre la compilación y otros que } \\
\text { ofrezcan seguridad; y la auditoría interna en la detección } \\
\text { y prevención de fraudes. }\end{array}$ \\
\hline Sector público & $\begin{array}{l}\text { Sistema de contabilidad gubernamental; control } \\
\text { gubernamental; y aspectos inherentes a los profesionales } \\
\text { que se desempeñan en el sector público. }\end{array}$ \\
\hline Sector público & $\begin{array}{l}\text { Sistema de contabilidad gubernamental; control } \\
\text { gubernamental; y aspectos inherentes a los profesionales } \\
\text { que se desempeñan en el sector público. }\end{array}$ \\
\hline Educación & $\begin{array}{l}\text { La formación del Contador Público Interamericano } \\
\text { hacia un currículo homogéneo; las carreras de posgrado } \\
\text { para el Contador Público; y entornos virtuales de } \\
\text { aprendizaje. }\end{array}$ \\
\hline $\begin{array}{l}\text { El valor razonable, su medición, requisitos de } \\
\text { revelación y su aplicación en Latinoamérica; la gestión } \\
\text { administrativa y financiera y el compromiso de } \\
\text { innovación del Contador Público. }\end{array}$ \\
\hline
\end{tabular}




\begin{tabular}{ll}
\hline \multicolumn{1}{c}{ Áreas generales } & \multicolumn{1}{c}{ Temas específicos por área } \\
\hline $\begin{array}{l}\text { Ética y ejercicio } \\
\text { profesional }\end{array}$ & $\begin{array}{l}\text { El Código de Ética de la profesión en cada país miembro } \\
\text { de AIC y su relación con el Código de Ética de la IFAC; } \\
\text { la Ética y el ejercicio profesional en la docencia y los } \\
\text { pensum de Contaduría; y la evolución y reglamentación } \\
\text { de la contaduría en cada país miembro de la AIC en el } \\
\text { marco de la globalización. }\end{array}$ \\
\hline $\begin{array}{l}\text { Tributación } \\
\text { y fiscalidad }\end{array}$ & $\begin{array}{l}\text { Análisis de la tributación de las empresas y grupos } \\
\text { la globalización comercial; y la infracción tributaria } \\
\text { como precedente del delito de Lavado de Activos y } \\
\text { Financiamiento del Terrorismo. }\end{array}$ \\
\hline Pymes & $\begin{array}{l}\text { La competencia y la certificación, una conducta ética } \\
\text { relevante del contador de Pymes; y análisis, aplicabilidad } \\
\text { e implementación de la guía de información financiera } \\
\text { para microempresas. }\end{array}$ \\
\hline $\begin{array}{l}\text { Sistemas y tecnologías } \\
\text { de información }\end{array}$ & $\begin{array}{l}\text { Oportunidades y riesgos en la aplicación de programas } \\
\text { de contabilidad en la gestión de la empresa Pyme; y } \\
\text { sistemas de control interno con énfasis en uso de TIC. }\end{array}$ \\
\hline
\end{tabular}

Fuente: elaboración propia con datos de la Trigésima Conferencia Interamericana de Contabilidad (2013).

En adición, para profundizar en los temas de vanguardia que en el presente y futuro próximo deben desarrollar los profesionales contables en beneficio de la sociedad y la educación, otro ejemplo de calidad a tomar como referencia es el Congreso Mundial de Contadores 2014 (World Congress of Accountants, 2014) realizado en Roma, Italia, bajo el lema "Visión 2020: aprendiendo del pasado, construyendo el futuro" y organizado por la Federación Internacional de Contadores, organismo cuyo objetivo es reunir y organizar a toda la profesión contable a nivel mundial mediante la estrecha vinculación con los Colegios de Contadores de todos los países y en estrecha colaboración con las grandes firmas internacionales de contadores; evento en el que se distinguieron cinco grandes áreas (ver tabla 7). 
Tabla 7. Áreas de investigación de relevancia de cara al futuro próximo en el entorno de la profesión contable

\begin{tabular}{cl}
\hline Área número & \multicolumn{1}{c}{ Temas específicos } \\
\hline $\mathbf{1}$ & $\begin{array}{l}\text { Convergencia internacional, marcos normativos nacionales } \\
\text { y mecanismos de adopción e implementación en normas } \\
\text { de información financiera, auditoría y aseguramiento de } \\
\text { información. }\end{array}$ \\
\hline $\mathbf{2}$ & Ética profesional \\
\hline $\mathbf{3}$ & $\begin{array}{l}\text { Estructuras organizativas de las prácticas y redes de } \\
\text { profesionales. }\end{array}$ \\
\hline $\mathbf{5}$ & $\begin{array}{l}\text { Desafíos y ventajas del aprovisionamiento contable en la gestión } \\
\text { financiera del sector público y la presentación de sus informes. }\end{array}$ \\
\hline & $\begin{array}{l}\text { Asesoría empresarial, proceso de toma de decisiones financieras, } \\
\text { reporte combinado de información financiera y no financiera. }\end{array}$ \\
\hline
\end{tabular}

\section{Conclusiones}

En consecuencia y con base a las características del plan de estudios de Contaduría y Alta Dirección descrito en detalle por la Universidad Popular Autónoma del Estado de Puebla, este ofrece contenidos diferenciados que ninguna de las demás ofertas educativas relacionadas con la Contaduría presenta, por lo que el programa en Contaduría y Alta Dirección brinda la posibilidad de un desempeño profesional para el estudiante en las disciplinas propias de la profesión contable, con un enfoque en la toma de decisiones orientado a promover la sustentabilidad de las entidades a las que preste sus servicios, de manera independiente o subordinada, y teniendo como pilar fundamental de su formación en contaduría un conocimiento profundo en el área de auditoría y la gestión de riesgos, adquiriendo a través de la Licenciatura en Contaduría y Alta Dirección ventajas competitivas con respecto a otras opciones de estudio similares, preparado para desempeñarse exitosamente en un entorno laboral en continuo cambio. 


\section{Referencias bibliográficas}

American Institute of Certified Public Accountants (2014). Generally Accepted Auditing Standards. American Institute of Certified Public Accountants: Carolina del Norte, Estados Unidos.

Asociación Mexicana de Intermediarios. (2014). Apartado AMIB certifica. Recuperado de http://www.amib.com.mx/certifica/0010_f1.asp

Asociación Nacional de Facultades y Escuelas de Contaduría y Administración. (2011). Ponencia central: Hacia un espacio común de educación superior en las facultades y escuelas de negocios en México. Recuperado de http://www. anfeca.unam.mx/docs/ponencias/2011/ponencia_central.pdf

Asociación Nacional de Universidades e Instituciones de educación Superior. (2014). Anuario estadístico digital 2012. Recuperado de http://www.anuies. $\mathrm{mx} /$ content.php? varSectionID $=166$

Association of Certified Fraud Examiners (2012). Report to de Nations on Occupational Fraud and Abuse. Association of Certified Fraud Examiners: Texas, Estados Unidos.

Banco de Pagos Internacionales. (2012). Principios Básicos para una supervisión bancaria eficaz. Comité de Supervisión Bancaria de Basilea. Banco de Pagos Internacionales: Basilea, Suiza.

Beuren, I. M., Hein, N., y Klann, R. C. (2008). Impact of the IFRS and US-GAAP on economic-financial indicators. Managerial Auditing Journal, 23(7), 632-649.

Cámara de Diputados. (2014). Paquete Económico para el Ejercicio Fiscal 2014. Gobierno de la República, México. Recuperado de http://www.diputados. gob.mx/PEF2014/

Carmona, S., y Trombetta, M. (2008). On the global acceptance of IAS/IFRS accounting standards: The logic and implications of the principles-based system. Journal of Accounting and Public Policy, 27 (6), 455-461.

Committee of Sponsoring Organizations of the Treadway Commission (2006). Internal Control over Financial Reporting: Guidance for Smaller Public Companies. Committee of Sponsoring Organizations of the Treadway Commission: Washington, Estados Unidos. 
Estudia. (2014). Licenciaturas en Ciencias Sociales y Administrativas en México, subcategoría "Contaduría”. Recuperado de http://licenciaturas.estudia.com. $\mathrm{mx} /$ licenciaturas+ciencias+sociales+administrativas+04.htm\#diez

Estudio comparativo de las Universidades Mexicanas. (2013). Estudio Comparativo de las Universidades Mexicanas. Recuperado de http://www.execum.unam. $\mathrm{mx} / \#$

Financial Accounting Standards Board. (2014). Standards. Recuperado de http:// www.fasb.org

González, J. (2010). Implementación inminente de las IFRS en México. BDO México. Recuperado de http://www.bdomexico.com/espanol/publicaciones/detalles/ pdf/Implementacion\%20Inminente\%20IFRS\%20en\%20Mexico_JGC.pdf

Hail, L., Leuz, C., y Wysocki, P. (2010). Global accounting convergence and the potential adoption of IFRS by the US (Part I): Conceptual underpinnings and economic analysis. Accounting Horizons, 24(3), 355-394.

International Accounting Education Standards Board. (2014). International Education Estandards. International Federation of Accountants. Recuperado de: http://www.ifac.org/education

Federación Internacional de Contadores (2014). Apartado Publications and Resources. Recuperado de http://www.ifac.org

IFRS Foundation. (2014). Apartado About us. Recuperado de http://www.ifrs.org Instituto Nacional de Estadística y Geografía. (2011). Clasificación mexicana de programas de estudio por campos de formación académica. Recuperado de http://www.inegi.org.mx/est/contenidos/espanol/metodologias/clasificadores/ CMPE_2011.pdf

Instituto Mexicano de Auditores Internos. (2014). Certificaciones. Recuperado de http://www.imai.org.mx/index.php?option=com_content\&view=article \&id=61\&Itemid $=56$

Instituto Mexicano de Contadores Públicos. (2014). Certificación por disciplinas. Recuperado de http://imcp.org.mx/category/certificacion-por-disciplinas . (2014). Nosotros. Recuperado de: http://imcp.org.mx . (2014). Áreas de Conocimiento. Recuperado de http://imcp.org.mx International Federation of Accountants. (2010). World Congress of Accountants: Accountants in the Next Decade. Evento realizado el 11 de noviembre en Kuala 
Lumpur, Malasia. Recuperado de https://launch.ifac.org/news-events/2010-11/ world-congress-accountants-accountants-next-decade

Michael Page México (2014). Reclutamiento especializado de ejecutivos. Recuperado de http://www.michaelpage.com.mx/

Microsoft. (2014). Certificaciones y exámenes. Recuperado de http://www.microsoft.com/learning/es-es/mos-certification.aspx

Observatorio Laboral de la Secretaría del Trabajo y Previsión Social. (2014). Base de datos sobre información por ocupaciones. Recuperado de http://www. observatoriolaboral.gob.mx/ola/content/common/reporteIntegral/busquedaReporte.jsf\#AnclaGrafica

Ocampo, J. A. (2009). Los derechos especiales de giro y el sistema mundial de reservas. Política Monetaria.

QS University Rankings (2013). QS Latin American University Ranking 2013. Recuperado de http://www.topuniversities.com/university-rankings/ latin-american-university-rankings/2013

Patiño, R. y Vásquez, N. (2013). Las características de los subsistemas contables de Colombia y México ante la convergencia a Normas Internacionales de Información Financiera. Número especial: cuatro años de convergencia contable: resultados, transformaciones y retos. Cuadernos de Contabilidad, 14 (36), 1009-1043.

Sistema Nacional de Información Estadística Educativa. (2014). Estadística e indicadores educativos por entidad federativa, Encuesta Nacional de Ocupación y Empleo, STPS-INEGI 2013. Recuperado de http://www.snie.sep.gob.mx/ indicadores_x_entidad_federativa.html

Trigésima Conferencia Interamericana de Contabilidad. (2013). Área Técnica. Recuperado de http://www.cicuruguay.com.uy/xxxcic/index.php/es/ area-tecnica/temario-general

World Congress of Accountants. (2014). Call for papers. Recuperado de: http:// www.wcoa2014rome.com/media/30/call-for-paper-wcoa2014.pdf 